\title{
Energy \&
}

\section{Environmental Science}

\section{Photoanodic behavior of vapor-liquid-solid-grown, lightly doped, crystalline Si microwire arrays $\dagger$}

\author{
Elizabeth A. Santori, ${ }^{d}$ James R. Maiolo III, ${ }^{d}$ Matthew J. Bierman, ${ }^{d}$ Nicholas C. Strandwitz, ${ }^{d}$ \\ Michael D. Kelzenberg, ${ }^{b}$ Bruce S. Brunschwig, ${ }^{a}$ Harry A. Atwater ${ }^{* b c}$ and Nathan S. Lewis *acd
}

Received 15th December 2011, Accepted 14th February 2012

DOI: $10.1039 / \mathrm{c} 2 \mathrm{ee} 03468 \mathrm{a}$

\begin{abstract}
Arrays of n-Si microwires have to date exhibited low efficiencies when measured as photoanodes in contact with a 1-1'-dimethylferrocene $\left(\mathrm{Me}_{2} \mathrm{Fc}^{+/ 0}\right)-\mathrm{CH}_{3} \mathrm{OH}$ solution. Using high-purity $\mathrm{Au}$ or $\mathrm{Cu}$ catalysts, arrays of crystalline $\mathrm{Si}$ microwires were grown by a vapor-liquid-solid process without dopants, which produced wires with electronically active dopant concentrations of $1 \times 10^{13} \mathrm{~cm}^{-3}$. When measured as photoanodes in contact with a $\mathrm{Me}_{2} \mathrm{Fc}^{+/ 0}$ $\mathrm{CH}_{3} \mathrm{OH}$ solution, the lightly doped $\mathrm{Si}$ microwire arrays exhibited greatly increased fill factors and efficiencies as compared to $\mathrm{n}-\mathrm{Si}$ microwires grown previously with a lower purity Au catalyst. In particular, the $\mathrm{Cu}$-catalyzed $\mathrm{Si}$ microwire array photoanodes exhibited open-circuit voltages of $\sim 0.44 \mathrm{~V}$, carrier-collection
\end{abstract}

${ }^{a}$ Beckman Institute, California Institute of Technology, 1200 E. California Blvd., Pasadena, CA 91125, USA

${ }^{b}$ Thomas J. Watson Laboratories of Applied Physics, California Institute of Technology, 1200 E. California Blvd, Pasadena, CA, 91125, USA. E-mail: haa@caltech.edu; Fax: +1 626 844-9320; Tel: +1 626-395-2197

'Member, Kavli Nanoscience Institute, California Institute of Technology, USA

${ }^{d}$ Division of Chemistry and Chemical Engineering, California Institute of Technology, 1200 E. California Blvd, Pasadena, CA, 91125, USA. E-mail: nslewis@caltech.edu; Fax: +1626395-8867; Tel: +1626395-6335 $\uparrow$ Electronic supplementary information (ESI) available: Additional information regarding the VLS growth of $\mathrm{Si}$ microwire arrays, four-point resistance measurements, photoelectrochemical measurements, concentration overpotential and resistance corrections, and optical measurements of $\mathrm{Si}$ wire array films. See DOI: $10.1039 / \mathrm{c} 2 \mathrm{ee} 03468 \mathrm{a}$ efficiencies exceeding $\sim 0.75$, and an energy-conversion efficiency of $1.4 \%$ under simulated air mass $1.5 \mathrm{G}$ illumination. Lightly doped $\mathrm{Cu}$-catalyzed Si microwire array photoanodes have thus demonstrated performance that is comparable to that of optimally doped ptype Si microwire array photocathodes in photoelectrochemical cells.

The structuring of semiconductors on the nano- and micro-scale is a promising approach for the fabrication of scalable and efficient devices for the production of electricity and fuels from sunlight. ${ }^{1-3}$ In contrast to a traditional geometry that is characterized by planar light absorbers and planar electrical junctions, wire-based architectures orthogonalize the directions of light absorption and carrier collection. ${ }^{4}$ Such a structure provides both a long optical path length for efficient light absorption and a short distance for minority-carrier collection, therefore allowing the incorporation of defective materials with short minority-carrier diffusion lengths into devices that can produce high energy-conversion efficiencies. Specifically, devicephysics modeling of radial junction $p-n$ Si microwires has predicted that crystalline $\mathrm{Si}$ microwire arrays can yield efficiencies comparable to those achieved by wafer-based planar $\mathrm{Si}$ solar cells, even for $\mathrm{Si}$ microwires that have a $1 \mu \mathrm{m}$ minority-carrier diffusion length. ${ }^{4}$

Arrays of crystalline p-Si microwires grown by the vapor-liquidsolid (VLS) process have demonstrated promising performance in regenerative ${ }^{5,6}$ and fuel-forming ${ }^{7}$ photoelectrochemical cells, as well as in photovoltaic devices. ${ }^{8,9}$ For example, p-type $\mathrm{Si}$ microwire array

\section{Broader context}

To make solar energy cost-competitive with fossil fuels and thus drive the large-scale deployment of photovoltaics, significant technological advances must be made to reduce the installed cost of photovoltaics to $<\$ 1 / \mathrm{Watt}$ peak. Recently, Si wire arrays grown by the vapor-liquid-solid technique have emerged as a promising technology for the fabrication of efficient and inexpensive photovoltaics, as well as for artificial photosynthetic devices. The thin-film Si wire array photovoltaic technology utilizes an atmospheric pressure, chemical vapor deposition growth process, inexpensive Si precursors, and earth-abundant catalysts, and produces flexible, crystalline Si solar cells that have the potential to approach the efficiencies of wafer-based crystalline Si solar cells. Herein we demonstrate improved performance of Si microwire array photoanodes in contact with a regenerative non-aqueous electrolyte that provides a conformal, high barrier-height contact to structured semiconductor materials. Hence, lightly doped $\mathrm{Cu}-$ catalyzed Si microwire array photoanodes can achieve performance comparable to that of optimally doped p-type Si microwire array photocathodes. 
photoelectrodes in contact with an aqueous methyl viologen $\left(\mathrm{MV}^{2+/+}\right)$ redox system have yielded open-circuit voltages $\left(V_{\mathrm{oc}}\right)$ approaching $0.45 \mathrm{~V}$ under $100 \mathrm{~mW} \mathrm{~cm}^{-2}$ of simulated air mass (AM) $1.5 \mathrm{G}$ illumination, with near-unity internal quantum yields, demonstrating the efficient radial collection of carriers in the wire-array geometry. Arrays of radial junction $\mathrm{n}^{+} \mathrm{p}-\mathrm{Si}$ microwires have demonstrated thermodynamically based photoelectrode energy-conversion efficiencies of $>5 \%$ for the production of $\mathrm{H}_{2}$ from $\mathrm{H}_{2} \mathrm{O}$. Analogous arrays in solid-state photovoltaic devices have achieved an efficiency of $7.8 \%$, with $V_{\text {oc }}$ exceeding $0.5 \mathrm{~V}$, under simulated AM $1.5 \mathrm{G}$ illumination.

In contrast, $\mathrm{n}-\mathrm{Si}$ microwire array photoanodes in contact with a 1-1'-dimethylferrocene $\left(\mathrm{Me}_{2} \mathrm{Fc}^{+/ 0}\right)-\mathrm{CH}_{3} \mathrm{OH}$ solution under simulated AM 1.5 conditions have only exhibited $V_{\text {oc }}$ values of $0.39 \mathrm{~V}$, in conjunction with low fill factors and low short-circuit photocurrent densities $\left(J_{\mathrm{sc}}\right)$, resulting in photoelectrode efficiencies, $\eta$, of $\sim 0.1 \%{ }^{10}$ Given that the $\mathrm{Me}_{2} \mathrm{Fc}^{+/ 0}-\mathrm{CH}_{3} \mathrm{OH}$ electrolyte in contact with planar, crystalline $\mathrm{n}-\mathrm{Si}$ photoanodes produces $V_{\mathrm{oc}}$ values that are only limited by bulk recombination/generation, ${ }^{11}$ the comparatively low performance of $\mathrm{n}$-Si microwire array photoanodes is presumably indicative of the inferior material quality of the $\mathrm{n}-\mathrm{Si}$ microwires. Two factors may have contributed to the poor electronic quality of the VLS-grown n-Si microwires: the purity of the catalyst used and the choice of metal catalyst. The n-Si microwire arrays were grown with a $99.999 \%(5 \mathrm{~N})$ Au VLS catalyst, ${ }^{10,12-14}$ as compared to the higher purity $99.9999 \%(6 \mathrm{~N}) \mathrm{Cu}$ catalyst that has been used to grow p-Si microwires. ${ }^{5,7,9,15-18}$ Uncontrolled impurities in the $5 \mathrm{~N} \mathrm{Au}$ catalyst produced microwires that had high variability in the observed electronically active dopant concentrations, $N_{\mathrm{d}}$, with values ranging between $1 \times 10^{14}$ and $1 \times 10^{20} \mathrm{~cm}^{-3}{ }^{16}$ Additionally, the use of $\mathrm{Au}$ as the VLS catalyst, as opposed to $\mathrm{Cu}$, may have limited the efficiency of the Si microwire arrays. Although both $\mathrm{Au}$ and $\mathrm{Cu}$ form mid-gap traps in $\mathrm{Si}$, in planar $\mathrm{Si}$ solar cells $\mathrm{Cu}$ has a less detrimental effect than $\mathrm{Au}$, with a minority-carrier lifetime degradation threshold concentration of $4 \times 10^{17} \mathrm{~cm}^{-3}$ for $\mathrm{Cu}$ as compared to $3 \times 10^{13} \mathrm{~cm}^{-3}$ for Au. ${ }^{19,20}$ The focus of this work was to determine whether the low photoelectrode efficiencies observed for $\mathrm{n}$-Si microwire arrays in contact with $\mathrm{Me}_{2} \mathrm{Fc}^{+/ 0}-\mathrm{CH}_{3} \mathrm{OH}$ are an inherent, fundamental property of the system or whether improved performance could be obtained through control over the electronic properties of the bulk and surface chemistry of $\mathrm{Si}$ wire array photoelectrodes.

We report herein the photoelectrochemical behavior of Si microwire arrays that have been fabricated using a $6 \mathrm{~N}$ VLS catalyst, for both $\mathrm{Au}$ and $\mathrm{Cu}$. The device performance of the Si microwire arrays was probed using the $\mathrm{Me}_{2} \mathrm{Fc}^{+/ 0}-\mathrm{CH}_{3} \mathrm{OH}$ junction, because this system provides a conformal contact to the microwires, and obviates the need to fabricate a diffused metallurgical junction. Additionally, the $\mathrm{Me}_{2} \mathrm{Fc}^{+/ 0}-\mathrm{CH}_{3} \mathrm{OH}$ system generates an inversion layer in contact with $\mathrm{n}-\mathrm{Si}$, and the resulting semiconductor/liquid interface has a low effective surface recombination velocity. ${ }^{21}$

To produce the desired photoanodes, arrays of square-packed $\mathrm{Si}$ microwires were grown on a planar $n^{+}-\mathrm{Si}(111)$ substrate using the VLS process, without dopants, but with $6 \mathrm{~N} \mathrm{Au}$ as the growth catalyst (see ESI $\dagger$ ). The resulting Si wires were oriented in the (111) direction, with diameters of 2.25-3.0 $\mu \mathrm{m}$ and heights of 65-75 $\mu \mathrm{m}$, with an average areal packing fraction $\left(\eta_{\mathrm{f}}\right)$ of $11.0 \%$. Four-point resistance and gate-dependent conductance measurements indicated that the undoped silicon microwires were nominally p-type, with resistivities of $800 \pm 700 \Omega-\mathrm{cm}$, corresponding to an acceptor concentration, $N_{\mathrm{a}}$, of $\sim 1 \times 10^{13} \mathrm{~cm}^{-3}$ (Figure S1).

Current density vs. potential $(J-E)$ measurements of Au-catalyzed Si microwire array photoanodes, and of control photoanodes in which the wires had been physically removed after growth on the $\mathrm{n}^{+}$Si substrate, were measured in contact with $200 \mathrm{mM} \mathrm{Me} 2 \mathrm{Fc}-0.4 \mathrm{mM}$ $\mathrm{Me}_{2} \mathrm{FcBF}_{4}$ in $\mathrm{CH}_{3} \mathrm{OH}$ under $100 \mathrm{~mW} \mathrm{~cm}{ }^{-2}$ of simulated AM $1.5 \mathrm{G}$ illumination (Fig. 1A). The $\mathrm{Si}$ wire array photoanodes exhibited $V_{\mathrm{oc}}=334 \pm 21 \mathrm{mV}, J_{\mathrm{sc}}=10.0 \pm 1.3 \mathrm{~mA} \mathrm{~cm}^{-2}$, and fill-factors, $f f=$ $0.34 \pm 0.05$, with a photoelectrode energy-conversion efficiency $\eta=$ $1.1 \pm 0.3 \%$. The $\mathrm{n}^{+}-\mathrm{Si}(111)$ control substrates for which the wires had been physically removed after growth produced $V_{\mathrm{oc}}=233 \pm 38 \mathrm{mV}$, $J_{\mathrm{sc}}=1.0 \pm 0.2 \mathrm{~mA} \mathrm{~cm}{ }^{-2}$, and $f f=0.20 \pm 0.04$. The observed properties of the $\mathrm{Si}$ microwire array photoelectrodes can therefore predominately be attributed to the behavior of the VLS-grown crystalline $\mathrm{Si}$ wires in contact with the $\mathrm{Me}_{2} \mathrm{Fc}^{+/ 0}-\mathrm{CH}_{3} \mathrm{OH}$ electrolyte.

The behavior of the same Au-catalyzed Si microwire photoanodes was also measured in contact with a higher concentration of the oxidized form of the redox couple, $25 \mathrm{mM} \mathrm{Me}_{2} \mathrm{FcBF}_{4}$, to reduce the concentration overpotential losses at the photoelectrode. The photoelectrodes were illuminated using an $808 \mathrm{~nm}$ laser diode, such that the $J_{\mathrm{sc}}$ value matched the value of $J_{\mathrm{sc}}$ that was obtained at low $\mathrm{Me}_{2} \mathrm{Fc}^{+}$concentrations under $100 \mathrm{~mW} \mathrm{~cm}{ }^{-2}$ of simulated AM $1.5 \mathrm{G}$ illumination. Fig. 1B shows the performance of the arrays in the presence of either 0.4 or $25 \mathrm{mM} \mathrm{Me} 2 \mathrm{FcBF}_{4}$, with the latter cell exhibiting a fill factor of $f f_{808}=0.47 \pm 0.04$ and an efficiency $\eta_{808}=$ $2.7 \pm 0.7 \%$. After correcting both the 0.4 and $25 \mathrm{mM} \mathrm{Me}_{2} \mathrm{FcBF}_{4} J-E$ data for concentration overpotential and uncompensated resistance losses, the corrected fill factor and photoelectrode efficiency values were $f f_{\text {corr }}=0.57 \pm 0.05$ and $\eta_{\text {corr }}=2.0 \pm 0.5 \%$, respectively (calculations in ESI $\dagger$ ). The corrected $J-E$ data are indicative of the inherent performance of the $\mathrm{Si}$ microwire arrays, without experimental artifacts arising from measurement in an unoptimized electrochemical cell configuration.

The photoelectrode efficiency of Si microwire arrays that were grown using the $6 \mathrm{~N}$-purity Au VLS catalyst represents a significant improvement relative to initial measurements of the photoanodic performance of n-Si microwire arrays in contact with the $\mathrm{Me}_{2} \mathrm{Fc}^{+/ 0}$ $\mathrm{CH}_{3} \mathrm{OH}$ system. However, the $V_{\text {oc }}$ of the $\mathrm{Si}$ microwire arrays grown with $\mathrm{Au}$ was still substantially less than the $V_{\mathrm{oc}}$ values produced by either $\mathrm{p}$-type or $\mathrm{n}^{+} \mathrm{p}$-Si microwire array photocathodes that were grown with $\mathrm{Cu}$ and tested in contact with the $\mathrm{MV}^{2+++}$ (aq) redox system. For Si microwires grown with a Au VLS catalyst, bulk Au concentrations up to $1.7 \times 10^{16} \mathrm{~cm}^{-3}$ have been previously measured, corresponding to the thermodynamic equilibrium concentration of $\mathrm{Au}$ in $\mathrm{Si}$ at the growth temperature. ${ }^{14}$ The concentration of Au within the wires thus greatly exceeded the degradation threshold concentration of $\mathrm{Au}$ in planar Si solar cells, and could have contributed to the lower $V_{\mathrm{oc}}$ values that were measured for wires that were grown with a Au catalyst. Indeed, Si microwire arrays that were grown by a Au-catalyzed VLS process have previously shown $V_{\text {oc }}$ values up to $500 \mathrm{mV}$ in photovoltaic device structures, but only after repeated thermal oxidation and etching steps that should getter $\mathrm{Au}$ at the surfaces of the Si wires. ${ }^{8}$

Given the low tolerance for $\mathrm{Au}$ in $\mathrm{Si}$ solar cells, $6 \mathrm{~N} \mathrm{Cu}$ was subsequently used for VLS-catalyzed $\mathrm{Si}$ wire growth. $\mathrm{Cu}$ catalyzed, hexagonally packed $\mathrm{Si}$ microwire arrays were fabricated without dopants, with the resulting wires being $2.0-2.5 \mu \mathrm{m}$ in diameter and $70-80 \mu \mathrm{m}$ in height, and providing an average areal packing fraction 
A)

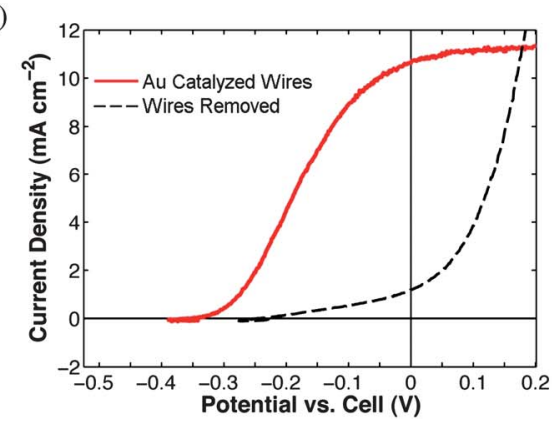

B)

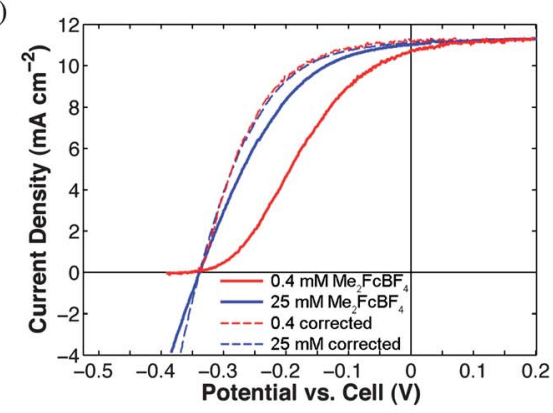

Fig. 1 Current density $v$ s. potential $(J-E)$ data for Au-catalyzed Si microwire array photoelectrodes in contact with the $\mathrm{Me}_{2} \mathrm{Fc}^{+/ 0}-\mathrm{CH}_{3} \mathrm{OH}$ redox system (a) under $100 \mathrm{~mW} \mathrm{~cm}{ }^{-2}$ of AM $1.5 \mathrm{G}$ illumination and (b) with varying amounts of varying amounts of $\mathrm{Me}_{2} \mathrm{FcBF}_{4}$, to demonstrate and correct for the electrochemical concentration overpotential resistance and series resistance losses within the cell.

$\left(\eta_{\mathrm{f}}\right)$ of $9.4 \%$ (Fig. 2). Similar to the Au-catalyzed wires, the $\mathrm{Cu}$ catalyzed wires were slightly p-type, with resistivities of $1000 \pm$ $600 \Omega$-cm, as measured by four-point resistance measurements, corresponding to $N_{\mathrm{a}}$ of $\sim 1 \times 10^{13} \mathrm{~cm}^{-3}$.

$J-E$ measurements of the Cu-catalyzed $\mathrm{Si}$ microwire arrays in contact with the $\mathrm{Me}_{2} \mathrm{Fc}^{+/ 0}-\mathrm{CH}_{3} \mathrm{OH}$ electrolyte under $100 \mathrm{~mW} \mathrm{~cm}{ }^{-2}$ of simulated AM 1.5 Gillumination (Fig. $3 \mathrm{~A}$ ) showed $V_{\mathrm{oc}}=437 \pm 8 \mathrm{mV}$, $J_{\mathrm{sc}}=7.9 \pm 0.5 \mathrm{~mA} \mathrm{~cm}^{-2}$, and $f f=0.40 \pm 0.02$, with a photoelectrode efficiency of $\eta=1.4 \pm 0.1 \%$. The Cu-catalyzed Si microwire array photoanodes measured herein exhibited a slightly smaller $J_{\mathrm{sc}}$ than the Au-catalyzed Si microwire array photoanodes, consistent with the $\mathrm{Cu}$ catalyzed wire arrays possessing a smaller areal packing fraction than the Au-catalyzed wire arrays. The $\mathrm{n}^{+}-\mathrm{Si}(111)$ control substrates with the wires physically removed produced $V_{\mathrm{oc}}=262 \pm 17 \mathrm{mV}, J_{\mathrm{sc}}=1.3 \pm$ $0.3 \mathrm{~mA} \mathrm{~cm}^{-2}$, and $f f=0.21 \pm 0.01$, again demonstrating that the wafer
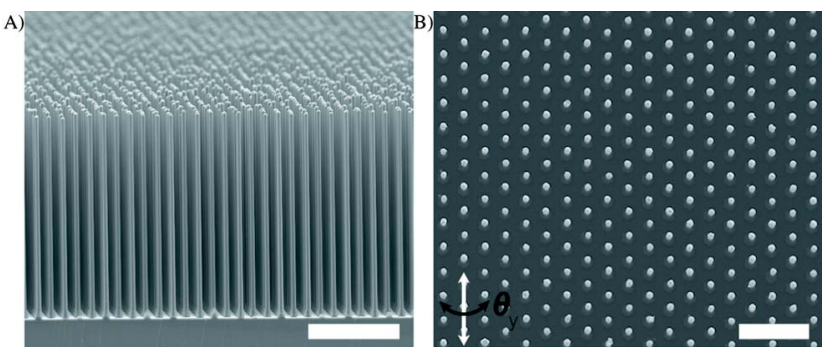

Fig. 2 (a) Side view scanning electron microscope image of a cleaved array of Si microwires, scale bar $=40 \mu \mathrm{m}$. (b) Top view of a Si microwire hexagonal array, and the noted axis of rotation $\theta_{\mathrm{y}}$, scale bar $=20 \mu \mathrm{m}$. substrate did not contribute substantially to the photoresponse of $\mathrm{Si}$ microwire photoelectrodes. The $\mathrm{Cu}$-catalyzed $\mathrm{Si}$ microwire array photoanodes measured under $808 \mathrm{~nm}$ illumination in contact with 25 $\mathrm{mM} \mathrm{Me}_{2} \mathrm{FcBF}_{4}$, to reduce concentration overpotential losses, exhibited a fill factor of $f f_{808}=0.60 \pm 0.02$ and an efficiency of $\eta_{808}=$ $3.4 \pm 0.2 \%$ (Fig. 3B). After correcting for concentration overpotential and uncompensated resistance losses, the corrected fill factor and efficiency were $f f_{\text {corr }}=0.61 \pm 0.04$ and $\eta_{\text {corr }}=2.1 \pm 0.1 \%$, respectively, for Si microwire photoanodes measured under AM 1.5 G illumination. Thus, the undoped $\mathrm{Cu}$-catalyzed $\mathrm{Si}$ wire array photoanodes in contact with $\mathrm{Me}_{2} \mathrm{Fc}^{+/ 0}-\mathrm{CH}_{3} \mathrm{OH}$ not only exhibited improved performance relative to the initial $\mathrm{n}-\mathrm{Si}$ wire array measurements, but also yielded efficiencies that were very similar to those observed for optimally doped $\mathrm{p}-\mathrm{Si}$ wire array photocathodes in contact with $\mathrm{MV}^{2+/}(\mathrm{aq})^{5,18}$

To further investigate the carrier-collection efficiency of the $\mathrm{Cu}-$ catalyzed $\mathrm{Si}$ microwire arrays, the external quantum yield, $\Gamma_{\mathrm{ext}}$, of $\mathrm{Si}$ microwire photoanodes in contact with $\mathrm{Me}_{2} \mathrm{Fe}^{+/ 0}-\mathrm{CH}_{3} \mathrm{OH}$ was recorded as a function of the incident angle of illumination $\left(\theta_{y}\right)$. The photoelectrodes were rotated about the $\theta_{\mathrm{y}}$ axis of the wire array, as shown in Fig. 2B, from $\theta_{\mathrm{y}}=0-60^{\circ}$. At normal incidence of illumination $\left(\theta_{\mathrm{y}}=0^{\circ}\right)$, the arrays showed the lowest external quantum yield, with $\Gamma_{\text {ext }} \sim 0.28$ under visible illumination (Fig. 4A), corresponding to high transmission through an array that had an average $\eta_{\mathrm{f}}=9.4 \%$. The prominent resonant peaks in the external quantum yield can be attributed to whispering-gallery modes in the hexagonal wires, in which light can circularly propagate at the periphery due to multiple total internal reflections. ${ }^{22,23}$ Despite the low packing fraction of wires, the arrays effectively collected $28 \%$ of the incident photons,
A)

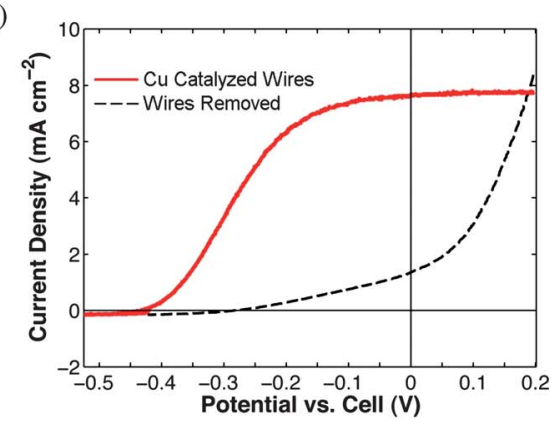

B)

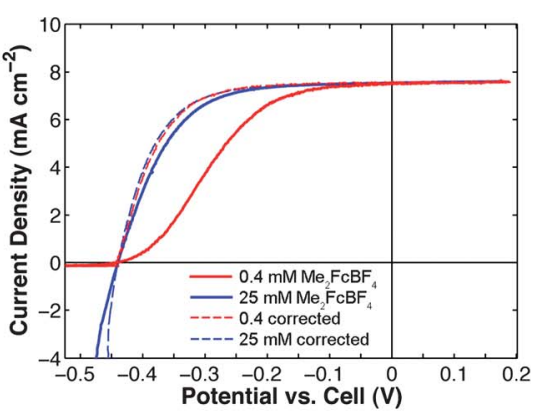

Fig. $3 J-E$ data for $\mathrm{Cu}$-catalyzed $\mathrm{Si}$ microwire array photoelectrodes in contact with the $\mathrm{Me}_{2} \mathrm{Fc}^{+/ 0}-\mathrm{CH}_{3} \mathrm{OH}$ redox system (a) under $100 \mathrm{~mW}$ cm ${ }^{-2}$ of AM $1.5 \mathrm{G}$ illumination and (b) with varying amounts of $\mathrm{Me}_{2} \mathrm{FcBF}_{4}$. 
(a)

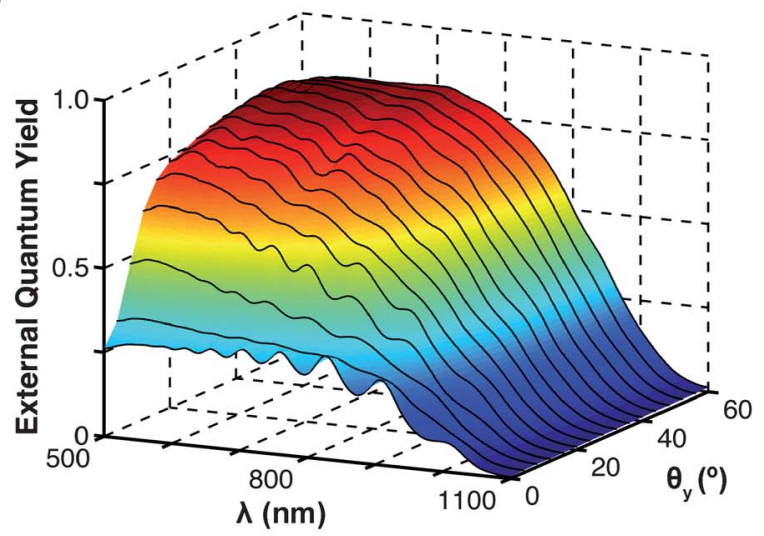

(b)

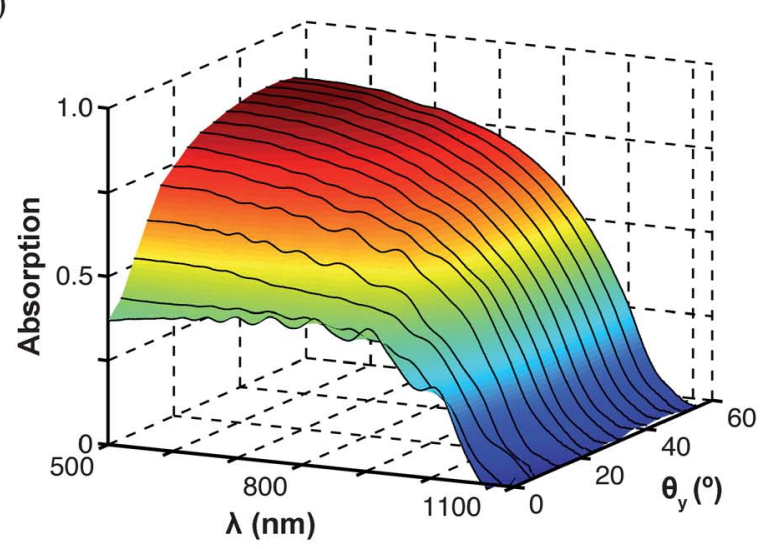

(c)

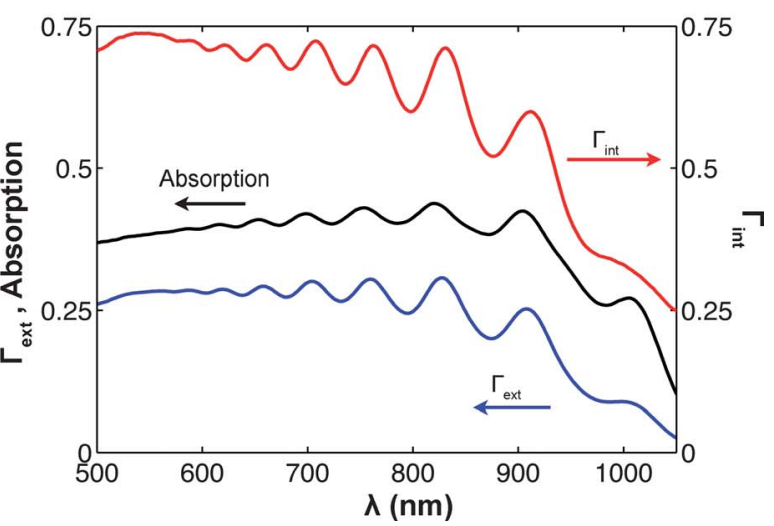

Fig. 4 Angle-resolved (a) external quantum yield and (b) absorption, and (c) calculated internal quantum yield at normal incidence, for $\mathrm{Si}$ microwire arrays.

demonstrating optical concentration within the array. The spectral response of the wire arrays strongly depended on the angle of incident illumination, with a peak of $\Gamma_{\mathrm{ext}}=0.86$ at $\theta_{\mathrm{y}}>52^{\circ}$. In contrast, photoanodes for which the $\mathrm{Si}$ wires had been physically removed from the substrate exhibited negligible photocurrent, with $\Gamma_{\text {ext }}<.03$. The current of such electrodes also did not vary with angle, further indicating that the degenerately doped $\mathrm{Si}$ substrate did not substantially contribute to the response of the $\mathrm{Si}$ wire array photoanodes.
The significant increase in $\Gamma_{\text {ext }}$ as $\theta_{\mathrm{y}}$ increased indicates that the $J_{\mathrm{sc}}$ of the wire arrays under AM $1.5 \mathrm{G}$ illumination was primarily limited by light absorption in the array, and not by carrier collection. Convolution of the spectral response at $\theta_{\mathrm{y}}>52^{\circ}$ with the AM $1.5 \mathrm{G}$ spectra resulted in a predicted $J_{\mathrm{sc}}$ value of $26 \mathrm{~mA} \mathrm{~cm}^{-2}$. As has been demonstrated recently, this calculated $J_{\mathrm{sc}}$ can be attained by incorporating light-trapping elements such as a back-reflector, antireflective coatings, and/or scattering particles into the device structure. ${ }^{9,24}$

To calculate the internal quantum yield, $\Gamma_{\text {int }}$, of the Cu-catalyzed $\mathrm{Si}$ microwire array photoanodes, optical absorption measurements as a function of wavelength and angle were performed on the same wire arrays that were used for collection of the external quantum yield data. An integrating sphere was used to perform optical transmission and reflection measurements on peeled films of wires that had been embedded in polydimethylsiloxane (PDMS), as described previously. ${ }^{24}$ As expected, the measured absorption was lowest at normal incidence, corresponding to large transmission through the sparsely packed, highly oriented array (Fig. 4B). The absorption rapidly increased with increasing angle of incident illumination, reaching a plateau value of 0.86 . The value of $\Gamma_{\text {int }}$ for the Si microwire array photoelectrodes was subsequently calculated by dividing the $\Gamma_{\text {ext }}$ at normal incidence by the absorption of the array at normal incidence. Fig. 4C compares the values of $\Gamma_{\text {ext }}$ and absorption at normal incidence, resulting in a peak $\Gamma_{\text {int }}$ value of $0.73 \pm 0.05$.

From the values of $\Gamma_{\text {int }}$ and the optical absorption coefficient $\alpha(\lambda)$, the minority-carrier diffusion length $L_{\mathrm{n}}$, for a planar device can be approximated by use of eqn (1). ${ }^{11,25}$

$$
\Gamma_{\mathrm{int}}=\frac{1}{1+\frac{1}{\alpha(\lambda) L_{\mathrm{n}}}}
$$

Analysis of $\Gamma_{\text {int }}$ for the Cu-catalyzed Si microwire array photoanodes in the near-infrared region $(800 \mathrm{~nm} \leq \lambda \leq 950 \mathrm{~nm})$, in which the optical penetration depth $\alpha^{-1}$ did not exceed the length of the wires, yielded an effective hole diffusion length, $L_{\mathrm{n} \text {,eff, }}$ of $75-85 \mu \mathrm{m}$. This value is not a true diffusion length, given that the assumptions of eqn (1) do not apply in a radial geometry, but rather a comparison to the diffusion length that would be needed to produce similar near-IR carrier collection efficiencies in a planar Si device structure (Fig. 5). The calculated $L_{\mathrm{n}, \text { eff }}$ value is significantly larger than the $30 \mu \mathrm{m}$ minoritycarrier diffusion length that has been measured previously for moderately doped, Cu-catalyzed, VLS -grown Si microwires. ${ }^{9,17}$ This observation further demonstrates the advantages of using a radial junction, which produces a longer effective diffusion length than the actual minority-carrier diffusion length, by extending the device response further into the near-IR region of the spectrum as compared to planar Si-based devices with comparable bulk electronic properties.

With $V_{\text {oc }}$ values of $0.44 \mathrm{~V}$, a photoelectrode energy-conversion efficiency of $\eta=1.4 \%$, and high carrier-collection efficiencies, the undoped $\mathrm{Cu}$-catalyzed $\mathrm{Si}$ microwire array photoanodes have demonstrated performance that is comparable to that of optimally doped p-type $\mathrm{Si}$ microwire array photocathodes. However, the measured $\Gamma_{\text {int }}$ deviated from the value of unity previously measured for p-type Si microwire photocathodes, and from the unity value that is predicted by radial junction theory for a wire having a radius smaller than the minority-carrier diffusion length. ${ }^{4}$ The $\Gamma_{\text {int }}$ of the wire array photoanodes at normal incidence was also lower than the 


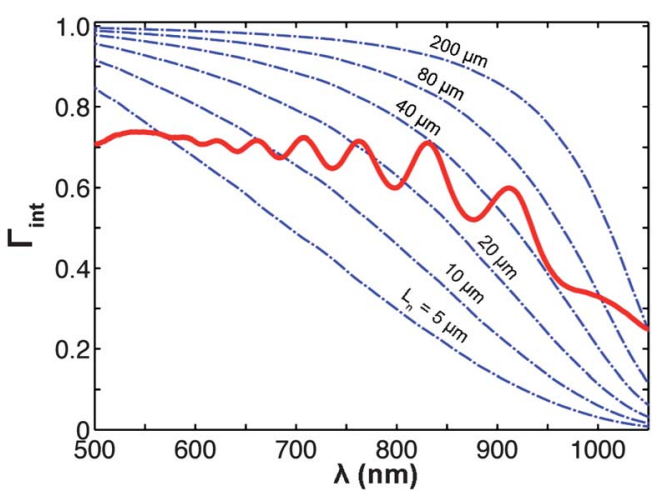

Fig. 5 A comparison of the measured $\Gamma_{\text {int }}$ of $\mathrm{Cu}$-catalyzed Si microwire array photoanodes and several calculated $\Gamma_{\text {int }}$ responses for planar $\mathrm{Si}$ photoelectrodes, with $L_{\mathrm{n}}$, ranging from 5-200 $\mu \mathrm{m}$.

$\Gamma_{\text {ext }}$ value that was measured at high angles, implying a change in $\Gamma_{\text {int }}$ with a change in the angle of incident illumination. The Si microwires, however, are not expected to have a minority-carrier diffusion length smaller than their $1.25 \mu \mathrm{m}$ radius, given that $30 \mu \mathrm{m}$ minority carrier diffusion lengths have been reported previously for $\mathrm{Cu}$-catalyzed VLS-grown Si microwires. These apparent discrepancies can be explained by the presence of $\mathrm{Cu}$ silicide located at the tops of the wires, as visualized by a high-contrast region in scanning electron microscopy images (Figure S2). This region persisted after chemical etching to remove the metallic $\mathrm{Cu}$ VLS catalyst, and varied in thickness from $200-900 \mathrm{~nm}$, depending on the cooling conditions after VLS growth. This silicide most likely acted as a region of low lifetime for carriers that were generated at the tops of the wires, where a significant fraction of the light is absorbed, ${ }^{26}$ thus decreasing the internal quantum yield, particularly at normal incidence. The quantum yield would therefore not only deviate from unity due to this electronically defective region, but would also vary as the excitation profile changed with incident angle of illumination, consistent with the observations reported herein.

Due to their very low dopant concentration, the $\mathrm{Si}$ wires are expected to be operating under high-level injection conditions, in which the concentration of photogenerated carriers exceeds the equilibrium concentration of majority carriers in the wire. ${ }^{27}$ The initial device physics model only encompassed wires under low-level injection that were not fully depleted, making the model potentially not applicable to undoped microwires operating under field-free conditions. Modeling of radial junction nanowire devices under highlevel injection conditions predicts that these devices should have poor carrier collection efficiencies, due to the full depletion within the nanowire resulting in large majority-carrier recombination losses. ${ }^{16,28}$ Work is currently underway to understand in more detail the properties of both nano- and microscale radial geometry devices with low dopant densities that are operating under high-level injection conditions.

\section{Acknowledgements}

We acknowledge BP, the Gordon and Betty Moore Foundation, Toyota, and the U.S. Department of Energy for financial support. NCS acknowledges the NSF for an American Competitiveness in Chemistry postdoctoral fellowship (CHE-1042006). The angleresolved optical characterization work was supported by the US
Department of Energy 'Light-Material Interactions in Energy Conversion' Energy Frontier Research Center Award (grant DESC0001293). We acknowledge critical support and infrastructure provided for this work by the Kavli Nanoscience Institute at Caltech.

\section{References}

1 B. Tian, T. J. Kempa and C. M. Lieber, Chem. Soc. Rev., 2009, 38, $16-24$.

2 A. I. Hochbaum and P. D. Yang, Chem. Rev., 2010, 110, 527-546.

3 M. G. Walter, E. L. Warren, J. R. McKone, S. W. Boettcher, Q. X. Mi, E. A. Santori and N. S. Lewis, Chem. Rev., 2010, 110, 6446-6473.

4 B. M. Kayes, H. A. Atwater and N. S. Lewis, J. Appl. Phys., 2005, 97, 114302.

5 S. W. Boettcher, J. M. Spurgeon, M. C. Putnam, E. L. Warren, D. B. Turner-Evans, M. D. Kelzenberg, J. R. Maiolo, H. A. Atwater and N. S. Lewis, Science, 2010, 327, 185-187.

6 J. M. Spurgeon, S. W. Boettcher, M. D. Kelzenberg, B. S. Brunschwig, H. A. Atwater and N. S. Lewis, Adv. Mater., 2010, 22, 3277-3281.

7 S. W. Boettcher, E. L. Warren, M. C. Putnam, E. A. Santori, D. Turner-Evans, M. D. Kelzenberg, M. G. Walter, J. R. McKone, B. S. Brunschwig, H. A. Atwater and N. S. Lewis, J. Am. Chem. Soc., 2011, 133, 1216-1219.

8 C. E. Kendrick, H. P. Yoon, Y. A. Yuwen, G. D. Barber, H. T. Shen, T. E. Mallouk, E. C. Dickey, T. S. Mayer and J. M. Redwing, Appl. Phys. Lett., 2010, 97, 143108.

9 M. C. Putnam, S. W. Boettcher, M. D. Kelzenberg, D. B. TurnerEvans, J. M. Spurgeon, E. L. Warren, R. M. Briggs, N. S. Lewis and H. A. Atwater, Energy Environ. Sci., 2010, 3, 1037-1041.

10 J. R. Maiolo, B. M. Kayes, M. A. Filler, M. C. Putnam, M. D. Kelzenberg, H. A. Atwater and N. S. Lewis, J. Am. Chem. Soc., 2007, 129, 12346-12347.

11 M. L. Rosenbluth and N. S. Lewis, J. Am. Chem. Soc., 1986, 108, 4689-4695.

12 M. D. Kelzenberg, D. B. Turner-Evans, B. M. Kayes, M. A. Filler, M. C. Putnam, N. S. Lewis and H. A. Atwater, Nano Lett., 2008, 8, 710-714.

13 B. M. Kayes, M. A. Filler, M. C. Putnam, M. D. Kelzenberg, N. S. Lewis and H. A. Atwater, Appl. Phys. Lett., 2007, 91, 103110.

14 M. C. Putnam, M. A. Filler, B. M. Kayes, M. D. Kelzenberg, Y. B. Guan, N. S. Lewis, J. M. Eiler and H. A. Atwater, Nano Lett., 2008, 8, 3109-3113.

15 M. C. Putnam, D. B. Turner-Evans, M. D. Kelzenberg, S. W. Boettcher, N. S. Lewis and H. A. Atwater, Appl. Phys. Lett., 2009, 95, 163116.

16 M. D. Kelzenberg, Ph.D., California Institute of Technology, 2010.

17 M. D. Kelzenberg, D. B. Turner-Evans, M. C. Putnam, S. W. Boettcher, R. M. Briggs, J. Y. Baek, N. S. Lewis and H. A. Atwater, Energy Environ. Sci., 2011, 4, 866-871.

18 E. L. Warren, S. W. Boettcher, M. G. Walter, H. A. Atwater and N. S. Lewis, J. Phys. Chem. C, 2011, 115, 594-598.

19 R. H. Hopkins and A. Rohatgi, J. Cryst. Growth, 1986, 75, 67-79.

20 J. R. Davis, A. Rohatgi, R. H. Hopkins, P. D. Blais, P. Raichoudhury, J. R. Mccormick and H. C. Mollenkopf, IEEE Trans. Electron Devices, 1980, 27, 677-687.

21 F. Gstrein, D. J. Michalak, W. J. Royea and N. S. Lewis, J. Phys. Chem. B, 2002, 106, 2950-2961.

22 T. Nobis, E. M. Kaidashev, A. Rahm, M. Lorenz and M. Grundmann, Phys. Rev. Lett., 2004, 93.

23 L. Y. Cao, J. S. White, J. S. Park, J. A. Schuller, B. M. Clemens and M. L. Brongersma, Nat. Mater., 2009, 8, 643-647.

24 M. D. Kelzenberg, S. W. Boettcher, J. A. Petykiewicz, D. B. TurnerEvans, M. C. Putnam, E. L. Warren, J. M. Spurgeon, R. M. Briggs, N. S. Lewis and H. A. Atwater, Nat. Mater., 2010, 9, 239-244.

25 W. W. Gartner, Phys. Rev., 1959, 116, 84-87.

26 M. D. Kelzenberg, M. C. Putnam, D. B. Turner-Evans, N. S. Lewis and H. A. Atwater, 2009 34th IEEE Photovoltaic Specialists Conference, Vols. 1-3, 2009, 001948-001953.

27 A. Luque and S. Hegedus, ed., Handbook of Photovoltaic Science and Engineering, Wiley, Chichester, England; Hoboken, NJ 2003.

28 J. M. Foley, M. J. Price, J. I. Feldblyum and S. Maldonado, Energy Environ. Sci., 2012, 5, 5203-5220. 